\title{
Research \& Practice of Stagewise Model in Clinical Medicine Teaching
}

\author{
Haogang Xue \\ Department of Orthopedic Surgery \\ Affiliated Hospital of Beihua University \\ Jilin, China \\ e-mail: haogangxue@163.com
}

\author{
Shougang Wang * \\ Department of Clinical Education \\ Affiliated Hospital of Beihua University \\ Jilin, China \\ e-mail: wsg97@126.com \\ Corresponding author
}

\begin{abstract}
For the teaching reform of Clinical Medicine in university, it is necessary to mainly reform the existing practice teaching system and to establish new practice teaching system and model in order to promote students' converting to thinking and creating type from the old memorizing and imitating type. To strengthen students' innovative consciousness and competence, we have altered the departed teaching style and carried out stagewise model in clinical medicine speciality teaching. In order to integrate theory with practice, practice teaching is emphasized. In clinical teaching, systematicness, integrality, refinement and science must be ensured to establish base of raising groundbreaking and applicative talents who adapt social development.
\end{abstract}

Keywords- stagewise model ; clinical medicine teaching

\section{INTRODUCTION}

The most important objective of tertiary medical education is to raise qualified medical talents. The reform of tertiary education has brought a very good moment for medical education and promoted the innovation and development of tertiary medical education tremendously. New advancement and the thoroughgoing change of modern science has raised higher request to tertiary medical education. To raise good diathesis medical talents adapting to the need of twenty-one century, how to optimize course system, reform teaching model, renew the teaching content and teaching means is very important.

The most important objective of tertiary medical education is to raise qualified medical talents. The reform of tertiary education has brought a very good moment for medical education and promoted the innovation and development of tertiary medical education tremendously. New advancement and the thoroughgoing change of modern science has raised higher request to tertiary medical education. To raise good diathesis medical talents adapting to the need of twenty-one century, how to optimize course system, reform teaching model, renew the teaching content and teaching means is very important.

At present, clinical practice is taken much count by Hesperian medical education. Medical students usually enter into hospital to be on probation from low-grade and obtain clinical knowledge and technical skill from clinical cases. This has been institutionalization and normalization. Nevertheless, by now in our country, most of the clinical medicine cultivation pattern is making students begun hospital practice only in grade five. Recently, because the stronger pressure on employment, some of the students have to prepare for taking part in the entrance exams for postgraduate schools, attending recruitment or look for job etc. These reasons occupy much time and energy of students and thus lead to the quality of practice has descended. Negative influence on raising good clinical medicine talents has also taken in some degree. Therefore, it is urgent priority to reform clinical speciality courses teaching mode and to strengthen the studyt of clinical practice technical skill in the clinical teaching.

\section{METHODS}

\section{A. Revise the cultivation program and increase the ratio of practice class}

Based on cultivation goal, the development tendency of modern medicine education and talent growth regularity, in the first class subject, optimize and reform entirely clinical speciality courses teaching mode and structure so as to make it more reflects modern education idea and innovation trend. This is benefit for students to form reasonable knowledge structure and to raise basic diathesis, personality development and adaptability. Our research priorities is to regulate the ratio of theory and practice of clinical speciality courses such as internal medicine, surgery, obstetrics and gynecology and paidonosology etc. Increase the time of practice during theory courses to create condition for teaching reform.

\section{B. Reform the teaching mode, execute the stagewise teaching}

Alter the traditionary teaching mode that only after all of clinical speciality courses have been finished, students can enter into clinical practice stage and execute the stagewise teaching mode. According to medical treatment special line of teaching hospital, carry out stagewise teaching in internal medicine, surgery, obstetrics and gynecology and paidonosology etc. After finishing the study of a system or organ's illness, Problem-Oriented Clinica Medicine Curriculu (PCMC) mode is applied. By the modern education technology 
such as simulation technique, virtual technology and standardized patients etc., the real clinical situation can be simulated. Practice and theory together, teaching and practice helps each other, which makes theory knowledge combines with relative clinical cases well so that the understand to theory knowledge in class can be enhanced. This method makes students understand clinical work and cases early and understand and grasp clinical speciality knowledge more accurately. We think highly of culturing students' practice ability. Aimed at clinical basic technical skill training, the rule of "three stages training examine" is taken.

- First stage: the basic operation to be standard. During the teaching process, students are divided into several groups, teachers guide students to do simulation system examination such as inspection, palpation, auscultation and percuss. The students are asked to master the standard and the normative method of physical examination.

- Second stage: aggrandize the training of clinical skills. The students are trained to get in touch with patients, search for typical cases, collect integrated medical history and accomplish all round physical examination. Instructional models such as multifunction smart human analogue are used in various clinical basic technical skill simulation training. Students are led into wards to communicate with patients preliminarily and trained to do interrogation and case-writing.

- Third stage: strengthen the cultivation of clinical mixed ability. Increase the teaching chance near hospital bed. Quantify every clinical skill items and implement them to every departments and disciplines respectively. Under the galenic guiding, students receive and administer patients independently. Eight indexes appraisement criteria is also carried out to test the students' clinical mixed ability so as to make a infarctate base for the future clinical work.

\section{Improve teaching method, increase teaching quality}

Buildup the idea that the main body of teaching is students, reform teaching method and renovate teaching means. The most important is to reform the traditional inoculation teaching mode in which teacher, class and text book are considered as center. Surrounding the goal that culture students' self-study and innovative competence, promote students' personality development, research the new teaching mode based on organs and systems. Strengthen the transverse and longitudinal relationship of knowledge. Extend PBL teaching method and develop method of enlightenment. According to the request of ministry of education, organize teachers to develop and make multimedia courseware actively. Multimedia is also used in imaging and intuitional teaching.

\section{Pilot program firstly, generalize new teaching method gradually}

Firstly, research \& practice of stagewise model in clinical medicine teaching was used in grade 2010 clinical medicine under graduate course, then generalize new teaching method gradually in all of the clinical medicine under graduate courses.

\section{RESULTS}

\section{A. Institute program of innovation}

Guided by the goal of raising general practitioners with high quality and high diathesis, the reform of instruction program which fits universities' characteristic has been formulated. Enhanced the clinical teaching quality and clinical practice depot construction. Emphasized the later teaching period of every medical specialties. Promoted the level of education and teaching, developed the quality of talents.

\section{B. Revise the cultivation schema}

Through enough investigation and discussion, we revised cultivation program and increased the ratio of clinical practice class in order to train students' clinical skill and ability. This has made the medicine students to have more sensibility recognition to medical and health work and physician occupation. Most of the students considered that the basic medical knowledge has been strengthened during the practice training and the medical skill has also been improved. They also thought that the new teaching mode helped them to improve the ability of clinical diagnose and treatment and their thinking mode of health care. (Table 1)

TABLE I. ARRANGEMENT OF FOUR SEMESTERS' COURSES

\begin{tabular}{|c|c|c|c|c|}
\hline Semester & Theory Class & PCMC & Practice & $\begin{array}{c}\text { Experimental } \\
\text { Class }\end{array}$ \\
\hline 1 & Introduction & 2 cases & & \\
\hline 2 & $\begin{array}{c}\text { Circulation System } \\
\text { Hemic \& Immune } \\
\text { Systems Digestive } \\
\text { System }\end{array}$ & $\begin{array}{c}4 \text { cases } \\
2 \text { cases } \\
3 \text { cases }\end{array}$ & $\begin{array}{c}\text { Practice in } \\
\text { hospital (20h) }\end{array}$ & $\begin{array}{c}\text { Morphology \& } \\
\text { Biotechnology } \\
\text { Experiments }\end{array}$ \\
\hline 3 & $\begin{array}{c}\text { Locomotor system } \\
\text { Endocrinium }\end{array}$ & 1 cases & $\begin{array}{c}\text { Practice in } \\
\text { hospital (20h) }\end{array}$ & $\begin{array}{c}\text { Function } \\
\text { Experiments }\end{array}$ \\
\hline 4 & $\begin{array}{c}\text { Nervous System } \\
\text { Genital \& } \\
\text { Reproductive System }\end{array}$ & 5 cases & cases & Practice in \\
hospital (20h) & $\begin{array}{c}\text { Etiology } \\
\text { Experiments }\end{array}$ \\
\hline
\end{tabular}

\section{Evaluation of teaching effect}

The result of examination and evaluation on stagewise teaching mode. Grade 2009, which were taught by traditional mode, is compared with Grade 2010, which were taught by new mode, in different aspects such as theory examination, clinical skill examine, clinical thinking of illness process and attitude. T-test was used to evaluate the results. The results shows that the difference is significance $(\mathrm{P}<0.001)$. (Table 2$)$

TABLE II. EXCELLENT RATE AND PASS RATE COMPARISON BETWEEN GRADE 2010 AND GRADE 2009

\begin{tabular}{|c|c|c|c|c|}
\hline & $\begin{array}{c}\text { Non-reform } \\
\text { classes } \\
(\%)\end{array}$ & $\begin{array}{c}\text { Reform classes } \\
(\%)\end{array}$ & $\boldsymbol{\mu}$ & $\mathbf{p}$ \\
\hline Excellent rate & 15 & 21 & 12.83 & $<0.001$ \\
\hline Pass rate & 49 & 9 & 2.76 & $<0.01$ \\
\hline
\end{tabular}




\section{SUMMARY}

In the $21^{\text {st }}$ century, medical education has turned from traditional biomedical model to modern biologypsychological- social medicine model. Meanwhile, as the development of meditech, demarcation of medicine special ward becomes more and more exquisite. The request to medical students' professional standard and practice experience also becomes stricter than before. Education of under graduate course is an important period during which advancing medical talents be cultured. The teaching quality standard of high medical education has raised a newer and higher request to clinical speciality course teaching stage.

At present, 5-year-program clinical medicine mainly follow the rule that in grade one and two, students study public courses in College of Basic Medicine, in grade three and four, they begin to study special subjects and have the proper clinical centralized practice, in grade five, students enter into hospital and have the production practice. This old mode bring the following abuse: nearly two years, almost all of clinical courses are rationalism and abstract. Related cases can be only described its symptoms and signs by teachers so that the cases are not concrete and without deep impression. Meanwhile, during the fifth practice stage, nearly without any theory knowledge, theory is out of keeping with practice, which is not benefit to understanding and mastering expertise. This phenomenon leads students to have limited clinical thought, contraction of academic visual field and practice disability etc.

According to our investigation, the ubiquitous problems are that students can't transform their parts and adapt clinical work quickly after enter into clinical practice. Students can't utilize clinical knowledge nimbly. Basic skill isn't very good. Some basic skills can not be finished adeptly. Operation is not standard. Analysis and resolve problems ability is not satisfactory either.

Therefore, besides finishing the theory courses and normal centralized practice which is regulated by teaching plan, reforming the teaching model of clinical speciality courses such as internal medicine and surgery and have the clinical basic skill simulation training is necessary. Make students enter into clinical wards early so as to provide students a "theory to practice, theory again to practice again" environment and condition. Undoubtedly, clinical early, clinical more, clinical repeatedly is a good way to improve medical students' clinical practice ability.

\section{REFERENCES}

[1] HUANG Jian- sheng, SHU Jia- ruo. Cultivation of the Practical Ability of Medical Students J. JOURNAL OF DALI UNIVERSITY, Vol.7 No.8 Aug. 2008:84-86.

[2] YUE Jie. Discussion on the Existing Clinical Teaching Problems through the Education Evaluation of the Undergraduate Course J. Researches in Medical Education, 2004.Vol. 3 No . 2: 43-45.

[3] CHEN Gang, LUO Dian - zhong. Emphasizing case - analyse teaching method, improving students' general ability J. Higher Education Forum, Dec1 20031No16: 112-114.

[4] Yaogang Li, Guoying Shi, Hongzhi Wang. Reform Practice Teaching, Culture Innovative Competence. J. Laboratory Study and Research. 2007, 26(11): 92-94

[5] Yidao Wang. Several Problems of Current Practical Teaching Reform. J.Practical Technology and Management. 2000,17(4):1-5.

[6] Xiaoying Ying, Hong Yuan, Yongzhong Du et al. The Practice Of pharmacy synthetic Designing Experiments. J. China High Medical Education. 2007(12):75-76

[7] Jayong Zhu, Ping Qi. Research of Interactive Production, Study and Research to Culture Application Pharmacy Talents. J. Pharmacy Education. 2011,27(2):1-3. 